\title{
Reflexões sobre a Reforma Sucupira e as Cartas de D. Dinis: é possível um diálogo da universidade na história?
}

\section{Reflections on the Sucupira Reform and Letters from D. Dinis: is a dialogue about the university in history possible?}

\section{Reflexiones sobre la Reforma Sucupira y las Cartas de D. Dinis: ¿es posible un diálogo de la universidad en la historia?}

Terezinha Oliveira $^{1}$

DOI: http://dx.doi.org/10.20435/serie-estudos.v22i46.1096

Resumo: O objetivo deste artigo é fazer uma análise da relevância da Universidade na história. Para isso tomamos como exemplo dois momentos específicos e distintos dessa Instituição, a Reforma Universitária de 1968, no Brasil, denominada Reforma Sucupira, e três Cartas de D. Dinis [1261-1325], monarca português, em fins do século XIII e início do XIV, que tratam do nascimento da Universidade em Portugal (JANOTTI, 1992; MATTOSO, 1997). Esses dois conjuntos de documentos nos permitem afiançar que tanto na Idade Média como no Brasil, na segunda metade do século XX, esta Instituição educativa ocupa lugar central na política dos governantes, seja na do rei medieval português, seja na de Costa e Silva, presidente brasileiro, da ditadura militar. Além desse conjunto de documentos, dialogaremos com intelectuais dos séculos XX e XXI que pesquisam essa instituição de ensino superior. Nossas reflexões têm como fio condutor evidenciar como a Universidade se constitui em peça-chave para o desenvolvimento sociocultural nos dois contextos e espaços, na medida que sua principal finalidade é formar pessoas para o convívio social. Nosso caminho teórico metodológico é a história e a história da educação, com forte inclinação à perspectiva historiográfica da primeira corrente da Escola dos Annales, especialmente quanto ao uso dos conceitos de permanência e longa duração.

Palavras-chave: universidade; formação humana; civilidade.

\begin{abstract}
The purpose of this article is to make an analysis of the relevance of the University in history. For this reason, we take as an example two specific and distinct moments of this Institution, the University Reform of Brazil in 1968, called the Sucupira Reformation, and three Letters of D. Dinis [1261-1325], Portuguese monarch, in the late thirteenth and early fourteenth, which dealt with the birth of the University in Portugal (JANOTTI, 1992; MATTOSO, 1997). These two sets of documents allow us to assert that in the Middle Ages and in Brazil in the second half of the twentieth century
\end{abstract}

${ }^{1}$ Universidade Estadual de Maringá (UEM), Maringá, Paraná, Brasil. 
this educational institution occupied a central place in the policy of rulers, be it in the Portuguese medieval king or in Costa e Silva, Brazilian president during the military dictatorship. In addition to this set of documents, we will dialogue with intellectuals of the 20th and 21st centuries who research this institution of higher education. Our reflections have as goal to show how the University is a fundamental piece for the socio-cultural development in the two contexts and spaces, as its main purpose is to train people for social interaction. Our theoretical methodological path is the history and history of education, with a strong inclination to the historiographical perspective of the first generation of the Annales School, especially regarding the use of the concepts of permanence and long duration.

Key words: university; human formation; civility.

Resumen: El objetivo de este artículo es hacer un análisis de la relevancia de la Universidad en la historia. Para ello, tomamos como ejemplo dos momentos específicos y distintos de esta Institución, la Reforma universitaria de 1968, en Brasil, Ilamada Reforma de Sucupira, y tres Cartas de D. Dinis [1261-1325], monarca portugués, a finales del siglo XIII y inicio XIV, que tratan del nacimiento de la Universidad en Portugal (JANOTTI, 1992; MATTOSO, 1997). Estos dos conjuntos de documentos nos permiten afirmar que, en la Edad Media y en Brasil, en la segunda mitad del siglo XX, esta institución educativa ocupa un lugar central en la política de los gobernantes, sea en el rey medieval portugués o en Costa e Silva, presidente brasileño y dictador militar. Además de este conjunto de documentos, dialogaremos con intelectuales de los siglos XX y XXI que investigan esta institución de enseñanza superior. Nuestras reflexiones tienen como orientación mostrar cómo la Universidad constituye una pieza clave para el desarrollo sociocultural en los dos contextos y espacios, pues su objetivo principal es entrenar a las personas para la interacción social. Nuestro camino metodológico teórico es la historia y la historia de la educación, con una fuerte inclinación a la perspectiva historiográfica de la primera corriente de la Escuela Annales, especialmente en lo que se refiere al uso de los conceptos de permanencia y larga duración.

Palabras clave: universidad; formación humana; civilidad.

A universidade faz parte da totalidade da vida social. A globalização invade todos os cantos do mundo, seja as microdimensões do cotidiano ou as grandes manifestações cada vez mais multiculturais das sociedades, influencia as novas configurações societais, altera as velhas noções de espaço e tempo na comunicação, expande as estruturas de informação, potencializa a mobilidade, imprime novos perfis no mundo do trabalho, impulsiona o acúmulo exponencial dos conhecimentos, gera mudanças nos campos das ciências e das tecnologias, produz o declínio das certezas, aumenta a complexidade nas relações humanas e na vida em geral. (DIAS SOBRINHO, 2005, p. 165).

\section{INTRODUÇÃO}

O objetivo deste artigo é tecer algumas reflexões acerca de percepções construídas, em alguns momentos da história da principal e mais antiga instituição 
de ensino superior no Ocidente: a universidade. Por se tratar de reflexões gerais, tomaremos como exemplo dois momentos específicos dessa Instituição do saber e, antecipadamente, já esclarecendo que não se trata de fazer/tecer comparações entre eles, mas destacar como uma mesma instituição humana pode ser pensada de modos distintos na história.

Para este estudo, elegemos como fontes o documento da Reforma Universitária de 1968, denominada Reforma Newton Sucupira, três Cartas sobre a fundação da Universidade em Portugal, em fins do século XIII, contidas no Chartularium Universitatis Portugalensis, e estudos de intelectuais contemporâneos.

O primeiro momento que tomaremos como referência será a reforma universitária de 1968 (ROTHEN, 2008; BOMENY, 2001), na qual buscaremos pôr em evidência o nosso tempo presente. O segundo momento será o nascimento da Universidade medieval no reino português. Para este momento, examinaremos algumas cartas de D. Dinis [1261-1325] com o propósito de destacar como esse monarca, conhecido por sua erudição e preocupação com a cultura do reino², zelava pelo bom desenvolvimento da Universidade. Utilizaremos, também, alguns estudos de Oliveira (2007), Janotti (1992) e Mattoso (1997).

Assim, esclarecemos que nosso estudo tem por intuito compreender, a partir dos exemplos de dois tempos históricos, como uma mesma instituição pode ser encarada por intelectuais a ela contemporâneos de modo muito distinto, ainda que tenha permanecido com o mesmo nome e, em tese, com a mesma finalidade, como é o caso da Universidade.

De fato, nesse texto pretendemos fazer um exercício teórico que aprendemos há algumas décadas (OLIVEIRA, 1997), com um dos mais eminente - infelizmente, renegado - professor de História da Sorbonne do século XIX, François Guizot [17871874]. Em uma de suas obras mais consagradas, História da Civilização na Europa, em sua sétima lição, para tratar do movimento de libertação das comunas medievais, usa o vocábulo 'liberdade' para debater sobre as diferenças entre o entendimento desse conceito entre os burgueses, habitantes das comunas medievais, no século XIII, e os burgueses da França, no século XVIII, contemporâneos da revolução francesa.

Para Guizot (1907), ainda que a palavra liberdade fosse a mesma, existia uma diferença abissal entre os sentido e significados de liberdade nesses dois tempos his-

\footnotetext{
${ }^{2}$ Acerca dessa preocupação de D. Dinis com a cultura do reino português, recomendamos a dissertação de Mariana Vieira Sarache (2016), intitulada Universidade, política e cultura em cantigas de D. Dinis século XIV).
} 
tóricos. Para os burgueses dos séculos XII e XIII, habituados ao jugo do senhor feudal, a luta pela liberdade restringia-se à sua conquista no interior da comuna. Assim, inda que tivessem de pagar impostos, corveias e pedágios aos senhores feudais, todas as vezes que saíssem das cidades/comunas, entendiam que o fato de poderem ir e vir, produzir e comercializar os seus produtos, nas corporações de ofícios, conferia-lhes 'autonomia' interna aos intramuros da cidade, essa era a conquista da liberdade. Diga-se de passagem, conquista que demandou muita luta e foi oficializada nas Cartas de Liberdade (THIERRY, 2005). Nesse cenário, os burgueses das comunas, nos séculos XII e XIII, ficavam felizes com a liberdade local e se sujeitavam com certa 'naturalidade' ao poder geral dos seus senhores, uma vez que esta era a forma com que estavam habituados a viver.

Contudo, para os burgueses do século XVIII, da França revolucionária, esse sentido de liberdade era a negação dela, uma vez que tudo no reino era feito pelos burgueses, o comércio, a agricultura, as invenções técnicas, enfim, toda a produção e circulação da riqueza. Esse quadro foi brilhantemente sintetizado no célebre texto panfletário do abade Sieyès (2002, p. 3) O que é o Terceiro Estado? ${ }^{3}$, no qual afirmou, de modo peremptório, que o Terceiro Estado era tudo, mas a nobreza, leia-se, os herdeiros dos senhores feudais, e a Igreja [os dois grandes poderes do medievo (TOCQUEVILLE, 1985)] continuavam a deter o poder político da nação e os burgueses entendiam que isto representava o cerceamento de seus direitos, logo, reivindicavam a liberdade total, particularmente a de assumirem o poder político da nação e de poderem ir e vir, sem que tivessem qualquer impedimento ou controle (OLIVEIRA, 1997).

Assim, tomando a maneira como Guizot analisou o processo de libertação das comunas e a eclosão da revolução francesa, a partir do conceito de liberdade, nós nos propomos a analisar a Universidade no Brasil contemporâneo e o seu surgimento no reino português em fins do século XIII e início do século XIV. Ressaltamos que, de modo algum, estamos nos comparando a esse grande magister de História da Sorbonne, mas sim, seguindo os seus passos de modo a elaborar uma reflexão da 'Casa' na qual vivemos e produzimos nossa vida acadêmica e formamos pessoas para serem, também, professores e pesquisadores, portanto, intelectuais formadores de opiniões.

${ }^{3}$ Título original: Qu'est-ceque le Tiers État? (1789). 


\section{REFLEXÕES SOBRE A REFORMA UNIVERSITÁRIA DE 1968}

Sabidamente, há um amplo debate, na historiografia brasileira, particularmente nos campos da história e da história da educação, acerca das origens da Universidade no Brasil. Alguns afirmam que a universidade do Rio de Janeiro inaugura o início desta instituição no país, outros se inclinam para a Bahia, outros, para a Universidade Federal do Paraná e outros, ainda, afirmam que o modelo mais acurado seria o da Universidade de São Paulo (USP), portanto esta representaria o nascimento da Universidade brasileira. Além desses debates existe, também, a possibilidade de eleger os projetos de universidade apresentados no Manifesto dos Pioneiros ou mesmo o projeto de Anísio Teixeira que é, a nosso ver, um dos mais importantes. Todavia, elegemos como marco temporal para a nossa análise dessa instituição o ano de 1968, a partir da Reforma de Newton Sucupira por entendermos que, em linhas gerais, a Universidade ainda continua assentada sobre as suas bases.

A maioria das universidades está organizada sob a forma de departamentos e inexiste o sistema de cátedra para a seleção do corpo docente, dentre outros aspectos. Isso, sem dúvida, não significa afirmar que a universidade brasileira do século XXI seja uniforme, uma vez que as diferenças entre as Instituições de Ensino Superior (IES) públicas e privadas são consideráveis, além das diferenças existentes entre as IES públicas federais e as IES estaduais. Além, é claro, dentro das próprias estaduais, as diferenças são acentuadas. Mas, de fato, não podemos negar o legado dessa proposta no cotidiano das Universidades brasileiras.

Ainda que quiséssemos desconsiderar a reforma de 1968 ou a sua forte presença nas estruturas da universidade brasileira, ela se mantém em nossa memória. Afinal, a base de dados na qual estão assentadas todas as informações sobre as pesquisas, em nível de pós-graduação stricto sensu, é uma homenagem a um dos seus principais ideólogos, Newton Sucupira. Também, a classificação dos periódicos científicos no Brasil, o Web Qualis, é divulgada na plataforma Sucupira, o que faz com que qualquer pessoa, minimamente vinculada ao ensino superior, acadêmicos, docentes ou interessados em informações sobre pesquisa e publicação precisam recorrer à Sucupira para obter suas informações. Direta ou indiretamente, a reforma está preservada na memória da comunidade universitária no país.

Feitas essas ressalvas, faremos algumas considerações sobre a reforma e a permanência na universidade brasileira.

As primeiras que destacamos referem-se ao fim da cátedra e à introdução do regime de dedicação exclusiva e tempo integral na carreira universitária. Essas duas 
mudanças proporcionaram ao ensino superior brasileiro um perfil muito diferente do que era até então. Segundo Lira "A Lei extinguiu a cátedra, introduziu o regime de tempo integral e dedicação exclusiva aos professores [...]" (LIRA, 2012, p. 1). Ao fazer isso criou a possibilidade de o docente tornar-se um pesquisador da instituição e com isso ampliar as condições de produção intelectual. Ao retirar o regime de cátedra, o ingresso na carreira docente tornou-se mais transparente, pois, hipoteticamente, o ingresso na instituição não seria mais por indicação do titular da cadeira, e sim por meio de concurso público. Ainda segundo, o autor, dentre outras medidas, a lei "[...] criou o sistema de créditos por disciplinas, instituiu a periodicidade semestral" (LIRA, 2012, p. 1). Inegavelmente, essas medidas proporcionariam um ensino superior mais democrático e, de fato, essas alterações foram incorporadas nas universidades brasileiras. Assim, paradoxalmente, no auge do regime militar, no ano de 1968, sob o governo de Costa e Silva, o mesmo presidente da república que sancionara o A1-5 em 1967 decreta uma lei, cujo primeiro capítulo trata da regulamentação da existência das IES e de assegurar, mediante a institucionalização, o direito a pesquisa e a autonomia do ensino superior.

Art. 10 ensino superior tem por objetivo a pesquisa, o desenvolvimento das ciências, letras e artes e a formação de profissionais de nível universitário.

Art. 20 ensino superior, indissociável da pesquisa, será ministrado em universidades e, excepcionalmente, em estabelecimentos isolados, organizados como instituições de direito público ou privado.

Art. 3 As universidades gozarão de autonomia didático-científica, disciplinar, administrativa e financeira, que será exercida na forma da lei e dos seus estatutos. (BRASIL, 1968, cap. 1, art. 1-3).

O objeto da lei é explicito, ou seja, permitir que a Universidade existisse e se desenvolvesse, ainda que a sociedade brasileira, como um todo, estivesse vivendo sob a égide da ditadura militar. Definir, no seu primeiro capítulo, que essa instituição teria liberdade para se autogerir e que as pessoas nela envolvidas 'gozarão de autonomia didático-científica' é, aos nossos olhos, um grande paradoxo. A universidade usufruiria, pela lei, uma liberdade que a sociedade não tinha.

Prosseguindo a leitura da lei, fica mais evidente que as estruturas organizacionais da Universidade, do século XXI, deitam suas raízes, na reforma de 1968.

Art. 11. As universidades organizar-se-ão com as seguintes características:

a).Unidade de patrimônio e administração;

b).estrutura orgânica com base em departamentos reunidos ou não em unidades mais amplas; 
c). unidade de funções de ensino e pesquisa, vedada a duplicação de meios para fins idênticos ou equivalentes;

d). racionalidade de organização, com plena utilização dos recursos materiais e humanos;

e). universalidade de campo, pelo cultivo das áreas fundamentais dos conhecimentos humanos, estudados em si mesmos ou em razão de ulteriores aplicações e de uma ou mais áreas técnico-profissionais;

f). flexibilidade de métodos e critérios, com vistas às diferenças individuais dos alunos, às peculiaridades regionais e às possibilidades de combinação dos conhecimentos para novos cursos e programas de pesquisa [...]. (BRASIL, 1968, art. 11).

A passagem acima indica que a lei buscou contemplar aspectos fundamentais da organização da universidade porque regulou, desde o estabelecimento dos departamentos até a sistematização de programas de ensino, que fossem flexíveis e atendessem às demandas de cada região. Registra-se, também, a preocupação em dar à universidade o seu papel primordial, tal como os documentos medievais já indicavam, o lócus de universalização do conhecimento.

Além da preocupação em modernizar o ensino superior, a lei revela ainda a intenção de ordenar a composição interna dessa instituição, buscando estruturar as suas diversas instâncias administrativas que a comporiam.

Art. 12 [...] §3으 O departamento será a menor fração da estrutura universitária para todos os efeitos de organização administrativa, didático-científica e de distribuição de pessoal, e compreenderá disciplinas afins.

Art. 13. Na administração superior da universidade, haverá órgãos centrais de supervisão do ensino e da pesquisa, com atribuições deliberativas, dos quais devem participar docentes dos vários setores básicos e de formação profissional. §1ㅇ A universidade poderá também criar órgãos setoriais, com funções deliberativas e executivas, destinados a coordenar unidades afins para integração de suas atividades.

§2ํ A coordenação didática de cada curso ficará a cargo de um colegiado, constituído de representantes das unidades que participem do respectivo ensino. Art. 14. Na forma do respectivo estatuto ou regimento, o colegiado a que esteja afeta a administração superior da universidade ou estabelecimento isolado incluirá entre seus membros, com direito a voz e voto, representantes originários de atividades, categorias ou órgãos distintos de modo que não subsista, necessariamente, a preponderância de professores classificados em determinado nível (BRASIL, 1968, art. 12-14).

O documento determina uma série de medidas reguladoras que são conservadas nas universidades do século XXI, a exemplo da definição do departamento como sendo a menor a unidade administrativa, o estabelecimento de colegiado de 
cursos definindo, inclusive, a participação de outras pessoas neste órgão, para que os docentes não tivessem hegemonia nas deliberações do curso, mantendo, desse modo, uma gestão participativa e democrática da comunidade da IES no Colegiado. Estes aspectos da composição da instituição nos mostra, de fato, que cada uma das IES do Brasil possui ainda as mesmas estruturas propostas pela reforma de 1968.

Depreendem-se da leitura da lei dois aspectos importantes acerca da história da universidade brasileira. O primeiro incide no fato de que os seus idealizadores se preocupavam com as condições em que se encontrava o ensino superior e buscaram o equipar ao que existia de mais avançado no Ocidente, tornando os professores pesquisadores, definindo as unidades administrativas e projetando um ensino que, mesmo salvaguardadas as grandes diferenças regionais, formasse pessoas com vistas a um conhecimento universal. O segundo é o caráter democrático e duradouro da proposta, o que nos permite retomar, mais uma vez, os princípios do professor Guizot, uma vez que o regime totalitário brasileiro permitiu que a universidade, a principal instituição de formação humana, em nível superior no Brasil, fosse erigida seguindo os princípios de um regime livre. A ditadura militar criou uma instituição que, se organizada de acordo com a reforma proposta, seria a antítese do seu governo, porque, na sua essência, promulgava a liberdade e a autonomia da universidade e cerceava a liberdade civil dos indivíduos.

\section{DIALOGANDO COM A HISTORIOGRAFIA}

Evidentemente, nessas quase cinco décadas que medeiam a promulgação da lei e a atual universidade, muitos intelectuais voltaram seus argutos olhares para essa instituição e procuraram apontar caminhos e fazer críticas às suas estruturas. Uma das críticas que ela sofre por parte dos pesquisadores do ensino superior reside no fato de ela estar voltada para a formação de pessoas para o mercado de trabalho (PEREIRA DE DEUS, 2009), por conseguinte, sua finalidade foi mercantilizada, como indicam Silva Júnior e Sguissardi (2005, p. 13).

Diante do que se procurou mostrar no plano histórico, torna-se fundamental refletir sobre as relações entre as esferas pública e privada, e, sobretudo, sobre a dimensão estatal/mercantil e a nova identidade da instituição universitária [...]. Nesse sentido, deve-se partir do princípio de que a liberdade e a igualdade são uma utopia iluminista e de que a propriedade privada e suas consequências são uma dura realidade no contexto da inserção do Brasil na imperial universalização do capitalismo. 
A crítica feita pelos autores acerca da mercantilização do ensino superior no Brasil está inserida em um conjunto de estudos que vinculam a crise da educação no ensino superior brasileiro ao processo de globalização do capital que teria posto por terra o ideal de igualdade social, na medida em que a universidade atenderia aos ditames do mercado e não da formação humana. Em virtude dessa inclinação, o ensino superior como condição de equalização social seria similar aos ideais iluministas de igualdade, uma utopia. Ainda que prosseguindo por outras pegadas históricas, mas tratando das questões acerca de uma possível equalização social, nos deparamos com as maduras reflexões de Azevedo (2013) acerca da trajetória conceitual e política dos conceitos de equalização e igualdade.

Em nosso diálogo com a historiografia. não poderíamos deixar de chamar para o texto dois intelectuais da universidade para participem das nossas reflexões. 0 primeiro deles é José Dias Sobrinho (2013; 2005), que, nas últimas décadas, tornou-se, a nosso ver, uma das maiores autoridades sobre o ensino superior no Brasil. O segundo é o filósofo Roberto Romano (2002). Ambos os intelectuais, do mesmo modo que os anteriores, tratam da instituição sob perspectivas que nos permitem entendê-la historicamente.

Dias Sobrinho, em diversos textos, indica a necessidade de pensar a universidade como parte integrante da sociedade, apresentando-a como elemento importante para a construção do bem comum da nação.

Educação como bem público é essencial para a formação de cidadãos conscientes e, correlativa e inseparavelmente, de profissionais qualificados. Formação cidadã e capacitação profissional são aspectos co-essenciais, mutuamente referenciados e solidariamente constitutivos do sujeito social. Cidadãos profissionais ética e tecnicamente responsáveis e qualificados são os principais. atores do fortalecimento econômico e, inseparavelmente, do desenvolvimento da nação. Nessa concepção, a economia é uma dimensão essencial da vida humana, mas não é a razão de ser da sociedade. Ao contrário, é a sociedade, guiada pelo valor moral do bem comum, que a deve determinar.

Discutir a educação como bem público e, então, como direito social, faz parte do conhecimento e da grande responsabilidade que as Instituições de Educação Superior (IES) têm relativamente à formação ética, científica e técnica dos indivíduos no marco da construção da sociedade. Os fins da educação com sentido público estão referidos à formação de indivíduos sociais, cuja construção pessoal integral se insere no plano mais amplo da construção da sociedade e, em termos universais, da dignificação da humanidade. (DIAS SOBRINHO, 2013, p. 110-1). 
Dias Sobrinho não separa a formação das pessoas no interior da universidade de seus respectivos papéis como sujeitos coletivos. Nesse sentido, o ensino superior teria uma finalidade relevante na constituição de uma sociedade mais equitativa porque permitiria que as pessoas oriundas dessas instituições, por meio do conhecimento aí adquiridos, pudessem agir de modo a buscar e fomentar, de acordo com suas ações cotidianas, melhorias sociais que, por seu turno, convergiriam para o bem comum da nação ${ }^{4}$. Sob este aspecto, o ensino superior seria, ainda segundo esse autor, de vital importância para qualquer Estado.

Roberto Romano também considera a universidade como um espaço fundamental à formação da pessoa e, justamente por isso, faz críticas severas às ações das pessoas que nela vivem e produzem suas reflexões. Do ponto de vista desse autor, a universidade sofre a mesma crise de ética pela qual passa a sociedade, pois os seus atores praticam ações que julga pouco éticas, uma vez que não prezam pelo conjunto de valores, princípios e regras próprios da instituição. É preciso destacar que essa entrevista foi feita há quinze anos, portanto, o país ainda não tinha sido estremecido pelas investigações políticas/criminais que têm sido divulgadas pela mídia há cerca de três anos. As políticas de combate ao plágio ou autoplágio (OLIVEIRA, 2015), também não haviam sido adotadas pelos órgãos de fomento, pelos programas de pós-graduações, pelos periódicos científicos, pelo MEC, dentre outros. Entretanto Romano já salientava a crise que atingia a universidade brasileira.

Tomemos duas situações destacadas pelo autor, a título de exemplo do que esse autor considera ausência de ética nas práticas acadêmicas. O primeiro é o que ele define como troca de favores.

Acho que a nossa vida social, inclusive a universidade e a pesquisa brasileiras, estão profundamente marcadas por traços éticos indesejáveis.

[...] Tomemos as relações de favor. Elas imperam nas políticas municipais e nacionais, na vida aquisitiva e mesmo na captação de recursos para a pesquisa. No Brasil o costume é esse: você tem um projeto objetivamente bom- do ponto de vista científico, acadêmico, metodológico-e, no entanto, sempre precisa ter alguém que dê a "mãozinha", interceda, esteja presente nos Conselhos, para que o seu projeto saia do anonimato. Mas o preceito democrático é justamente o anonimato, o valor da coisa, e não da pessoa. As fórmulas conhecidas, como o "sabe com quem está falando" e o QI (quem indica?), infelizmente modelam

\footnotetext{
${ }^{4}$ Impossível não vincular as formulações de Dias Sobrinho acerca do conhecimento como um aspecto essencial da produção do bem comum com as ideias de Aristóteles (1985), em Ética à Nicômaco, e de Tomás de Aquino (2016), em A Unidade do Intelecto contra os averroístas.
} 
boa parte das relações científicas, acadêmicas. Esse ponto ético da cultura brasileira merece ser reformulado, para que não exista mais a guerra de todos contra todos, a formação de pequenos grupos de influências para troca de favores... Só quem desconhece a realidade social brasileira e a realidade social das universidades e das próprias Fundações de Pesquisa ousa dizer que nelas não existem esses nexos de influência pessoal. (ROMANO, 2002, p. 99).

Na passagem acima, explicita-se que, na aprovação das pesquisas, especialmente, mas não somente naquelas que envolvem recursos financeiros, o que prevalece é a relação de pessoalidade, e não o mérito científico. De acordo com Romano, a aprovação de dada pesquisa depende do grau de solidariedade de grupo, e não da qualidade e viabilidade da proposta. Nesse quadro desenhado pelo autor, o mérito é facilmente suplantado se o proponente possui uma ampla rede de relações de amizade. Assim, o que teria validade não é a qualidade da pesquisa, mas a receptividade e o nome do autor. Essa característica da pesquisa no Brasil se constituiria em um retrocesso para ciência no país e, com isso, toda a população é prejudicada, uma vez que um bom projeto pode ficar adormecido em uma gaveta qualquer, porque o proponente não possui uma ampla rede social de pesquisas. Por outro lado, projetos sem mérito podem ser aprovados porque o proponente possui amigos no comitê ou uma ampla rede de amizades. O que resultaria no mesmo quadro que atinge a política e muito das relações interpessoais na sociedade brasileira, ou seja, o famoso QI, quem indica.

Outro exemplo que emprestamos de Romano para traçar nosso quadro sobre a universidade brasileira é a questão do anonimato dos referees. Para o autor, muitas atitudes antiéticas são praticadas e ficam ocultas por trás do véu do anonimato.

Outro ponto gravíssimo do ponto de vista ético: temos Fundações que operam segundo o pressuposto do anonimato do parecerista. Mas este último raramente assume todas as dimensões da ética e da moral. Muitas vezes- e cada vez mais - o parecerista utiliza o anonimato para combater inimigos ou adversários do ponto de vista metodológico, ideológico e, até mesmo, doutrinário. Muitos não têm dúvidas em cortar recursos para a pesquisa dos que pensam de forma diferente. Esta é uma fonte de tensão enorme na comunidade acadêmica. E dizem tratar-se de uma prática com preceitos éticos. Para mim, trata-se de algo profundamente imoral. Defendo, como uma parte da democratização da pesquisa brasileira, o fim do anonimato do parecerista. Esta é uma atitude de responsabilidade social, porque numa Fundação de direito público, com recursos públicos, não há direito ao anonimato. A alocação- ou não- de dinheiro deve ser examinada pelo público, porque é ele que paga. $O$ anonimato é profundamente antiético, é imoral e viceja sob a capa da ética. (ROMANO, 2002, p. 99). 
Eis aqui apresentado um problema muito sério para a comunidade acadêmica brasileira, que é ausência de ética na avaliação entre pares. Romano toca em uma questão que é grave, pois, envolto nas brumas, muitos projetos importantes são reprovados e muitos projetos de baixa qualidade são aprovados por agências de fomento ou mesmo para publicações em periódicos científicos. Essa prática oculta que expressa perseguições teóricas, políticas ou mesmo pessoais atinge a sociedade como um todo, pois os financiamentos envolvem recursos públicos, portanto oriundos de tributos pagos pelo povo que podem ser mal empregados ou não empregados por razões de ordem particular. Exatamente por isso, Romano propõe que os avaliadores possam/devam ser identificados porque isso amenizaria a força das perseguições, por conseguinte, das práticas antiéticas, na medida em que retiraria das brumas o referir. Segundo o autor e, indubitavelmente, concordamos com ele, essa medida resultaria em um bem público porque os financiamentos às pesquisas, em tese, não sofreriam o crivo da pessoalidade e existiria a transparência na avaliação dos pares. Ao sair do anonimato, o referir [avaliador] seria o responsável pelo bom ou mau gasto do erário público. Em boa medida, seria tão responsável quanto o proponente do projeto, em relação aos resultados do financiamento da pesquisa proposta, avaliada e aprovada. Por outro lado, a reprovação ética e meritocrática de uma proposta de pesquisa traria duplo proveito à sociedade porque impediria o dispêndio de dinheiro público para um estudo que, de início, não apresentaria chances de um bom resultado e, por outro, colaboraria com a formação do pesquisador que, por meio da avaliação, poderia aprimorar sua proposta.

Os dois exemplos que trouxemos de Roberto Romano, sobre ações praticadas por professores e pesquisadores do ensino superior, evidenciam caminhos pouco éticos dos nossos pares e nos permite observar que precisamos estimular amplos debates acerca da principal instituição de ensino superior do país, pois, ainda que se tenha decorrido praticamente meio século entre a promulgação da Lei 5.540, por Costa e Silva, temos muitos problemas que precisam ser solucionados para que a Universidade se torne um espaço de formação humana que, por seus conhecimentos, busque o bem comum, como propõem Dias Sobrinho e Roberto Romano.

\section{D. DINIS E OS PRINCÍPIOS DA UNIVERSIDADE MEDIEVAL NO REINO PORTUGUÊS}

Com a análise da reforma de 1968 no Brasil e das considerações de dois importantes estudiosos sobre a função social da universidade, destacamos essa instituição como espaço de produção de conhecimento e de civilidade. Nas três cartas de D. 
Dinis, também encontramos esses princípios, ainda que o momento histórico seja muito distinto. Assim, mudou o tempo, o cenário, o espaço geográfico, mas a universidade manteve a finalidade de formar as pessoas em prol do desenvolvimento da sociedade. E mais, seja no Brasil ou no reino português medieval, o governante do Estado tem papel fundamental nos caminhos da universidade.

A primeira Carta de D. Dinis é datada de 1 de março de 1290 e tem por objetivo explicitar como a Universidade era de vital importância para o reino português (JANOTTI, 1992; MATTOSO, 1997; VERGER, 2001; OLIVEIRA, 2009; 2007), por isso se dirige ao papa solicitando que autorizasse a fundação de um Estudo Geral em Lisboa.

D. Dinis, pela graça de Deus, Rei de Portugal e do Algarve, a quantos a presente carta virem, muito saudar [1290 - 1 de março]

Reconhece-se que aquele admirável tesouro de ciência, que, quanto mais se derrama, mais aumenta a sua uberdade, ilumina espiritual e temporalmente o Mundo, porque, com a sua aquisição, todos nós, os católicos, conhecemos a Deus nosso Criador, e em nome de seu Filho Nosso Senhor Jesus Cristo abraçamos a fé católica, e também porque, sendo Nós e os outros príncipes, seus servos, obedecidos de nossos súbditos, a vida deste é, por virtude dessa obediência, informada com a ministração da Justiça ensinada por aquela ciência. Por isso, para dizermos com o Profeta, a pedimos ao Senhor. Rogar-lhe-emos, para habitarmos em Sua morada. Ora, desejando Nós, enriquecer nossos Reinos com este precioso tesouro, houvemos por bem ordenar, na Real Cidade de Lisboa, para honra de Deus e da Santíssima Virgem Sua Mãe e também do Mártir S. Vicente, cujo santíssimo corpo exorna a dita cidade, um Estudo Geral, que não só munimos com cópias de doutores em todas as artes, mas também roboramos com muitos privilégios. Mas, porque das informações de algumas pessoas entendemos que alguns virão de várias partes ao nosso dito Estudo, se gozarem de segurança de corpos e bens. Nós, querendo desenvolvê-lo em boas condições, prometemos, com a presente carta, plena segurança a todos os que nele estudam ou queiram de futuro estudar, e não permitiremos que lhes seja cometida ofensa por algum ou alguns de maior dignidade que sejam, antes, com a permissão de Deus, curaremos de os defender de injúrias e violências. Além disso, quantos a ele vierem nos acharão em suas necessidades de tal modo generosos, que podem e devem fundamentalmente confiar nos múltiplos favores da Alteza Rei. (CHARTULARIUM UNIVERSITATIS PORTUGALENSIS, 1969, p. 11-2).

D. Dinis destaca a importância de o reino ter sua universidade, porque dela sairiam os melhores homens para o reino, aqueles que tinham o domínio das artes. Em virtude disso, solicita que seja permitida sua criação em Lisboa e, em contrapartida, prometia ao Papa que os homens dessa 'Casa' teriam toda a proteção física e moral 
do rei, pois entendia que Portugal não poderia desenvolver-se caso não tivesse uma Universidade para formar homens que possibilitassem o florescimento das artes no reino. Mas, não era somente de homens das ciências que D. Dinis pretendia prover o reino. Ele tinha grande interesse em formar advogados e administradores que pudessem 'modernizar', como ele afirmara, iluminar o reino.

A segunda Carta de D. Dinis é de 1291, e ela trata de uma doação do rei de casas para que a 'Casa' tivesse um lugar próprio e definitivo para se fixar.

Carta de D. Dinis doando duas casas, sitas na Pedreira, onde existiam as casas para as escolas [1291 - 22 de julho]

Dom Denis pela graça de Deus Rey de Portugal e do Alguarue. a quantos esta carta vyrem faço saber que Eu dou a dom Martim Gil e a todos seus successores por herdamento duas casarias em aquelterreo meu da par da padreyrahu eu mandey fazer as casas pera as scolas e em cada hũa dessas Casarias a em longo. viij. braças e. v. em ancho as quaes casarias partem contra aguiomcon as casarias de Lourenço scola e contra aurego e contra aurego e contra ouriente e contra ouciente som carreyras puluegas dou a esse dom Martim e a todos seus successores essas casarias como dicto e por herdade liures e quites de todas rrenda e de todo tributo pera todo sempre e que elles façam e compram delas toda sauo ontade e que a mjm nem a meus successoresnomdemende outra rrenda nem façam ende outro foro como mj fazem das outras casarias desse logarmays façam delas o que Ihysprouguer como de seu herdamentoproprio e por estopoysnomvijr em duuydadejende ao dicto dom Martim Gil esta carta que a tenha el e todos seus successores. Em testemoyo. (CHARTULARIUM UNIVERSITATIS PORTUGALENSIS, 1969, p. 23-4).

A Carta trata, especificamente, da definição de um lugar físico para a instituição. Por isso, D. Dinis afirma que a doação deve ser mantida continuamente. É preciso ressaltar que, na Idade Média, não havia a ideia de propriedade privada como na modernidade ou na atualidade; o que existia era a posse de bens e, por ocasião da morte da pessoa que tinha 'ganhado' a posse do bem [leia-se imóvel], ele retornava ao doador ou aos seus herdeiros. Portanto, para assegurar que as casas doadas se tornassem definitivamente lugar do Estudo Geral/Universidade, o rei certificou-se de que as pessoas, por se dedicarem ao estudo e produzirem 'proveito' para o reino, teriam o direito da posse no presente e a sua manutenção por meio da hereditariedade. Essa observância precisa ser feita porque ela explicita os privilégios que os homens da Universidade passaram a receber do rei.

A terceira 'Carta' de D. Dinis evidencia o zelo do rei em proteger as pessoas que se dedicavam aos estudos. Ela é datada de 1309. 
Carta de D. Dinis declarando que recebe em sua guarda e defendimento todos os escolares do Estudo Geral de Coimbra [1309 - 15 de fevereiro]

Per que Recebe os scollares em sua guarda e defendimento. Dom denjs etc a quantos esta carta virem faço saber que eu recebo em mjnha guarda et em mjnha encomenda e sob meu defendimento todo llos scollares que steuerem no studo de cojnbra e aos que pera elle vierem emquanto forem e vierem pera elle porque mando e defendo que nenhũunom faça mal a esses scollares nem os feira nem os traga mal E aquel que o fizesse peitarmia os meus incoutos de bj mil ssoldos e o seu corpo staria a mjnha mercee E em testimunho // desto dey aa vnjuersidade dos scolares desse estudo esta mjnha carta /.

Dante em lixboa xb dias de feuereiro elrrey o mandou pello custodio afonsomartijnz a fez era de mjliij $R$ bij anos. (CHARTULARIUM UNIVERSITATIS PORTUGALENSIS, 1969, p. 48).

Essa Carta trata especificamente da salvaguarda pessoal e física dos alunos e mestres da Universidade. O Reino colocava sob sua proteção todos os universitários de Coimbra, afirmando que ninguém poderia atacá-los de forma alguma e, se algum súdito não obedecesse a essa ordem, seria punido por D. Dinis. O documento evidencia a preocupação do monarca em se posicionar a favor dos estudantes em detrimento dos demais súditos. É preciso esclarecer que, na Idade Média, a proteção real era um privilégio muito especial e, se o Rei editasse uma carta com este objetivo, é porque considerava ser a vida dos universitários prioridade do seu governo. Sabidamente essas vantagens aos homens da universidade causaram muitos problemas nas cidades, pois os habitantes comuns sentiam-se prejudicados por esses privilégios, sem contar que as pessoas da universidade, por terem esses privilégios, promoviam distúrbios na comunidade e, na maioria das vezes, não podiam ser punidos pelas 'autoridades locais' os administradores da comuna/cidade.

Assim, as três Cartas de D. Dinis exprimem que, no outono da Idade Média, no reino português, os homens da Universidade usufruíam de privilégios reais que foram vitais para a fundação e o estabelecimento dessa Instituição. O rei, por seu turno, estabeleceu esses apanágios por entender que o conhecimento era condição para o florescimento do reino. Não se tratou, portanto, de propiciar vantagens sem objetivos bem definidos, ou sem exigências, mas, sim, de uma ação política com a finalidade de criar as condições para o desenvolvimento material, político, científico e cultural do reino. Logo, foi uma ação política de um 'bom' governante. 


\section{CONSIDERAÇÕES FINAIS}

Ao escrevermos este texto, seguindo os caminhos de Guizot quando compara o conceito de liberdade entre os habitantes das comunas nos séculos XII e XIII com os do século XVIII, pretendíamos evidenciar que a leitura/análise da universidade, nossa 'Casa' do ensino superior, tem como objetivo destacar que essa instituição só pode ser compreendida com as lentes da história. Com efeito, trata-se de uma instituição humana, criada com a finalidade de responder a determinadas necessidades sociais específicas. Não se trata, portanto, de um locus destituído da vontade dos homens, particularmente dos homens que a habitam, no sentido literal, em relação à época medieval - pois alunos e mestres de fato moravam no espaço acadêmico - e, metafórico, em relação ao século XXI. A universidade, como lugar de ensino, de pesquisa e de extensão, como é conhecida atualmente, só pode existir por estar vinculada aos homens reais e com finalidades objetivas em consonância com as necessidades do seu tempo.

Se D. Dinis estabeleceu privilégios de proteção física, se doou à 'Casa' em direito hereditário, foi porque o reino precisava dos homens da Universidade para promover o florescimento do reino. Assim, não foi o acaso ou a vontade de um governante simpático às causas do saber que levaram à criação de vantagens que distinguiram os homens de saber dos demais súditos. D. Dinis visava a um bem maior: o florescimento de Portugal e, em vistas desse fim, não hesitou em os tornarem diferentes dos demais, inclusive no que diz respeito à posse de bens materiais. Um monarca feudal, no interior de uma teia complexa de dominus feudo-vassálico não titubeou em criar regras especlficas para os homens da universidade por almejar um bem maior.

Tendo como parâmetro esSe exemplo do monarca português, torna-se possível compreender porque, em pleno governo militar, foi proposta, no Brasil, uma reforma democrática da Universidade que, diga-se de passagem, permanece, em linhas gerais, até o século XXI. Assim, ainda que a reforma Sucupira possa nos parecer anacrônica em relação ao contexto em que foi promulgada, ela também atendeu a necessidade da época, ou, pelo menos, do projeto que o governante brasileiro pretendia que fosse atendido, por meio dos homens da universidade. Por isso criou a dedicação exclusiva à pesquisa, a contratação integral e o fim do sistema de cátedras, dentre outras mudanças.

Desse modo, sendo uma intelectual desta 'Casa' há quase três décadas, entendo que, tanto para D. Dinis como para Costa e Silva, os homens da universidade possuíam papÉis a desempenhar e exatamente, por isso editaram leis que possibilitaram que os universitários respondessem aos interesses da sociedade. Logo, pertencer à universidade implica agir em conformidade com os interesses da sociedade. Por conseguinte, pensar essa instituição como lugar de produção de melhoria social 
e, ainda, como expressão de um dado tempo histórico. A universidade medieval é medieval por excelência; a universidade proposta pela Reforma de 1968 respondia ao movimento dos homens das décadas de 1960, 1970; a universidade brasileira do século XXI espelha os homens deste século, inclusive no que se refere às práticas não éticas, como nos mostrou Roberto Romano. Se quisermos mudar o seu sentido e significado, podemos tomar como exemplo os homens burgueses do século XVIII, que não aceitaram como liberdade o entendimento dos burgueses dos séculos XII e XIII e que, segundo Guizot, não aceitaram mudar as características das suas instituições. Por isso mudaram a sociedade, fizeram a revolução francesa.

\section{REFERÊNCIAS}

ARISTÓTELES. Ética a Nicômoco. Brasília: UnB, 1985.

AZEVEDO, M. L. N. Igualdade e equidade: qual é a medida da justiça social? Avaliação, Campinas, SP, v. 18, n. 1, p. 129-50, 2013.

BOMENY, H. Newton Sucupira e os rumos da educação superior. Brasília: Paralelo 15, 2001.

BRASIL. Presidência da República. Casa Civil. Lei n. 5.540, de 28 de novembro de 1968. Fixa normas de organização e funcionamento do ensino superior e sua articulação com a escola média, e dá outras providências. Diário Oficial da União, Brasília, DF, 23 nov. 1968. Disponível em: < http://www.planalto.gov.br/ccivil_03/leis/L5540.htm>. Acesso em: 23 ago. 2017.

CHARTULARIUM UNIVERSITATIS PARISIENSIS (1288-1377). Lisboa: Instituto de Alta Cultura, 1969. v. 1.

DIAS SOBRINHO, J. Educação superior: bem público, equidade e democratização. Avaliação, Campinas, SP, v. 18, n. 1, p. 107-26, 2013.

. Educação superior, globalização e democratização: qual universidade? Revista Brasileira de Educação, Rio de Janeiro, n. 28, p. 164-73, 2005.

GUIZOT, F. História da civilização na Europa. Lisboa: Parceria Antonio João Maria, 1907. 2 v. JANOTTI, A. Origens das universidades: singularidade do caso português. São Paulo: Edusp, 1992.

LIRA, A. T. N. As bases da Reforma Universitária da ditadura militar no Brasil. In: ENCONTRO REGIONAL DE HISTÓRIA DA ANPUH-RIO- OFÍCIO DO HISTORIADOR: ENSINO E PESQUISA, 15., 2012, Rio de Janeiro. Anais... Rio de Janeiro: ANPUH, 2012. p. 1-9. Disponível em: <www. encontro2012.rj.anpuh.org/>. Acesso em: 30 ago. 2017.

MATTOSO, J. A universidade portuguesa e as universidades europeias. In: História da Universidade em Portugal. Coimbra: Universidade de Coimbra, 1997. v. 1, p. 3-29.

OLIVEIRA, T. Produção/publicação científica: algumas reflexões sobre ética. In: PORTO, C.; FERRONATO, C.; LINHARES, R. A produção científica brasileira na contemporaneidade: exigências e interlocuções. Salvador: Edufba, 2015. p. 111-32. 
- Memória e história da educação medieval: uma análise da Autentica Habita e do Estatuto de Sorbonne. Avaliação, Campinas, SP, v. 14, n. 3, p. 683-98, 2009.

. Origem e memória das universidades medievais a preservação de uma instituição educacional. Varia Historia, Belo Horizonte, v. 23, n. 37, p. 113-29, jan./jun. 2007.

. Guizot e a Idade Média: civilização e lutas políticas no século XIX. 1997. 407f. Tese (Doutorado em História) - Universidade Estadual Paulista Júlio de Mesquita Filho (Unesp), Assis, SP, 1997.

PEREIRA DE DEUS, M. A. Gestão da contra-reforma neoliberal nas universidades federais brasileiras. In: JORNADA DE INVESTIGACIÓN HISTÓRICO SOCIAL RAZÓN E REVOLUCIÓN, 8., 2009, Buenos Aires. Anales... Buenos Aires: Facultad de Filosofia y Letras, UBA, 2009.

ROMANO, R. Entrevista com Roberto Romano. Interface: Comunicação, Saúde, Educação, Botucatu, SP, v. 6, n. 10, p. 97-110, 2002.

ROTHEN, J. C. Os bastidores da Reforma Universitária de 1968. Educação e Sociedade, Campinas, SP, v. 29, n. 103, p. 453-75, maio/ago. 2008. Disponível em: <http://www.scielo. br/pdf/es/v29n103/08.pdf>. Acesso em: 17 jul. 2017.

SARACHE, M. V. Universidade, política e cultura em Cantigas de D. Dinis (Século XIV). 2016. 116 f. Dissertação (Mestrado em Educação) - Universidade Estadual de Maringá (UEM), Maringá, PR, 2016.

SIEYÈS, E. J. Qu'est-ce que le Tiers état? Paris: Éditions Du Boucher, 2002.

SILVA JÚNIOR, J. R.; SGUISSARDI, V. A nova lei de educação superior: fortalecimento do setor público e regulamentação do privado/mercantil ou continuidade da privatização e mercantilização do público? Revista Brasileira de Educação, Rio de Janeiro, n. 29, p. 5-27, 2005.

THIERRY, A. Carta XIII. Sobre a libertação das comunas. In: MENDES, C. M.; OLIVEIRA, T. (Org.). Formação do Terceiro Estado. As comunas: coletânea de textos: François Guizot, Augustin Thierry e Prosper Barante. Maringá, PR: Eduem, 2005. p. 51-63.

TOCQUEVILLE, A. O antigo regime e a revolução. Brasília: UnB, 1985.

TOMÁS DE AQUINO. A unidade do intelecto contra os averroístas. São Paulo: Paulus, 2016. VERGER, J. Cultura, ensino e sociedade no Ocidente nos séculos XII e XIII. Bauru, SP: Edusc, 2001.

\section{Sobre a autora:}

Terezinha Oliveira: Professora Titular do Departamento de Fundamentos da Educação e do Programa de Pós-Graduação da Universidade Estadual de Maringá. E-mail: teleoliv@gmail.com

\section{Recebido em maio de 2017}

Aprovado para publicação em setembro de 2017 